\title{
RESIDUAL STRESS STUDY ON WELDED SECTION OF HIGH STRENGTH Q460 STEEL AFTER FIRE EXPOSURE
}

\author{
W.Y. Wang ${ }^{1, *}$, G. Q. Li ${ }^{2}$ and Y. Ge ${ }^{3}$ \\ ${ }^{1}$ Associate Professor, School of Civil Engineering, Chongqing University, Chongqing , China; \\ ${ }_{2}^{2}$ Professor, State Key Laboratory for Disaster Reduction in Civil Engineering, Tongji University, Shanghai, China \\ ${ }^{3}$ Assistant Engineer, Architecture design institute for civil air defense of Shandong province, Jinan, China \\ *(Corresponding author: E-mail: wywang@cqu.edu.cn)
}

Received: 2 September 2013; Revised: 3 July 2014; Accepted: 29 September 2014

\begin{abstract}
The residual stress magnitude and distribution of mild carbon steel sections at room temperature has been widely studied. Little investigation has been performed on residual stress of high strength steel sections, especially at elevated temperatures and after fire exposure. The fire exposure and elevated temperature have great influence on the residual stress distribution. This paper presents the experimental study of residual stress of welded high strength steel H-shaped section after fire exposure. The residual stress at room temperature was compared with that after fire exposure both for mild steel and high strength steel. The residual stress of welded high strength Q460 steel section was also simulated by finite element analysis and the validated finite element model was employed to analysis the residual stress of high strength steel section at elevated temperatures. It is found that the residual stress of high strength steel section after fire exposure decreases significantly and the residual stress variation should be considered on fire resistance design of high strength steel structures.
\end{abstract}

Keywords: Residual stress; high strength steel; elevated temperature; finite element analysis

\section{INTRODUCTION}

High strength steel (HSS, yield strength $\geqq 460 \mathrm{MPa}$ ) has been widely used in many buildings, spatial structures and bridges by providing benefits when compared with regular strength steel, such as reducing structural dead load and dimensions of members, saving material and space [1]. It is well known that residual stresses exist in most structural steel members induced by welding, flame cutting, uneven cooling or cold forming during processes of manufacture and fabrication. Although the internal equilibrium residual stresses are not detrimental to the resistance of cross section for steel members, the presence of residual stress will significantly influence the stiffness of compression members and shorten the fatigue life of steel members under periodical load or dynamic load [2].

In order to understand the effect of residual stress on the structural behavior of steel structures, the magnitudes and distributions of regular strength steel sections have been extensively investigated in the past decades [3]. In recent years, the residual stress in stainless steel section and high strength steel section has also been studied. An experimental program to quantify the residual stresses in stainless steel sections from three different production routes has been carried out by Gardner et al [4] and comprehensive residual stress distributions was obtained for three hot rolled angles, eight press braked angles and seven cold rolled box sections. The residual stress of high strength Q460 steel in box section was experimental investigated by Li et al. [5] by adopting both sectioning and hole-drilling methods and the corresponding simplified residual stress pattern was proposed. However, the research work on residual stresses of Q460 welded sections after fire exposure or at elevated temperatures is very limited. It is expected that the residual stresses of Q460 members at elevated temperature are rather different from that at room temperature, since the stress-strain curves and high-temperature material properties of Q460 are different from that at room temperature [6]. For this reason, the influence of residual stress on ultimate bearing capacities of compressed HSS members at elevated temperatures will be different from that at room temperature. 
For the fire safety design of HSS members in civil engineering structures, especially for compressed steel members, it is important to evaluate the magnitudes and patterns of residual stress distribution for HSS members at elevated temperatures.

In the present paper, residual stress magnitude and distribution for welded high strength Q460 steel of $\mathrm{H}$-shaped section was tested at room temperature and after fire exposure by utilizing sectioning method technique, which is a destructive method and was widely adopted in residual stress measuring. To compare the decrease of residual stress of high strength steel with mild steel, mild steel Q235 was also tested at room temperature and after fire exposure. The residual stress of high strength steel section after fire exposure was also simulated by finite element analysis and the validated finite element model was employed to analysis the residual stress of high strength steel section at elevated temperatures. In the previous fire resistance design of steel columns, the assumption of residual stress keeping constant was adopted due to lack of data of residual stress at elevated temperatures. Therefore, the residual stress variation at elevated temperatures of high strength steel sections is very helpful to determine the load bearing capacity of high strength steel columns in fire condition.

\section{MATERIAL PROPERTIES}

In the testing specimen, high strength Q460 steel is used. The mechanical properties of this steel at room temperature are obtained by coupon test and the yield strength is $\mathrm{f}_{\mathrm{y}}=585 \mathrm{MPa}$, ultimate strength is $f_{u}=660 \mathrm{MPa}$ and the elastic modulus is $\mathrm{E}=2.12 \times 105 \mathrm{MPa}$. At elevated temperatures, the mechanical properties are referred to literatures [6-7]. In the finite element analysis, in addition to mechanical properties, the thermal properties including conductivity, specific heat, thermal expansion coefficient and enthalpy, are used and the values of them are adopted by EC3 [8]. The material properties are plotted in Figure 1.

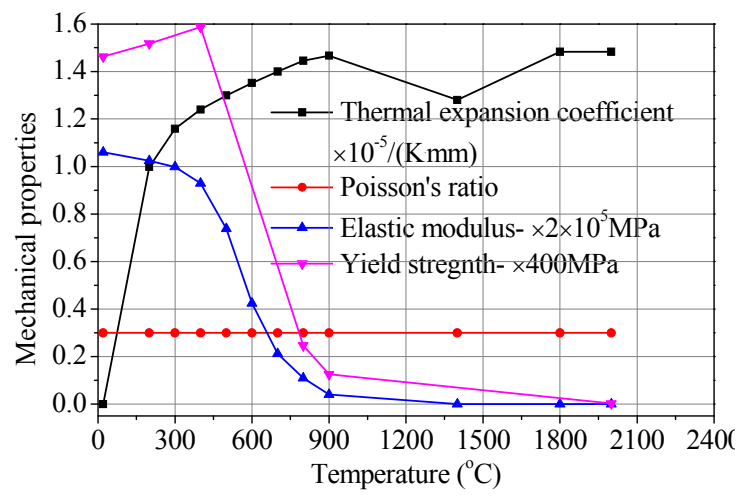

(a) Mechanical properties

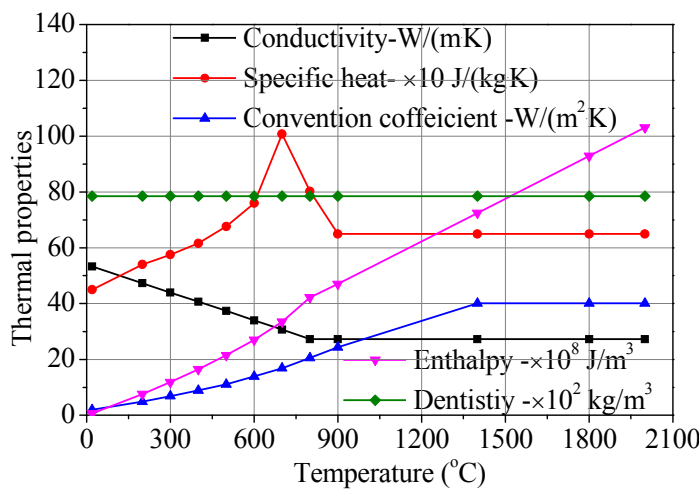

(b) Thermal properties

Figure1. Properties of High Strength Q460 Steel

The enthalpy is computed by

$\Delta H(T)=\int_{0}^{T} \rho c d T$

where, $\Delta H(T)$ is increment of enthalpy at temperature $T ; \rho$ is mass of steel and $\mathrm{c}$ is specific heat. 


\section{EXPERIMENTAL PROGRAM}

\subsection{Experimental Technique}

Techniques to measure residual stresses may be classified as either destructive or non-destructive. Non-destructive methods include X-ray, neutron or electron diffraction, ultrasonic methods and magnetic methods. Destructive methods rely on the measurement of deformations due to the release of residual stresses upon removal of material from the specimen. Sectioning is the principal destructive technique used to measure residual stresses in structural members. This method has been used extensively to analyze residual stresses in structural carbon steel, aluminum and stainless steel sections and is adopted in this study. Its advantages of adequate, accurate and economical have been proven with requirement of proper care in the preparation of the specimen and the measurement procedures [9]. A comprehensive description of the different techniques and their potential for measuring residual stresses has been presented in literature [10].

\subsection{Specimen and Instruments}

The testing specimen of $\mathrm{H}$-shaped section is fabricated with welded high strength Q460 steel plate of $8 \mathrm{~mm}$ in thickness and the dimension of cross section is $\mathrm{H} 200 \times 195 \times 8 \times 8$ (height $\times$ width $\times$ flange thickness $\times$ web thickness). One $2.32 \mathrm{~m}$ column in length was welded and it was cut into two parts at the middle section. One is used to prepare specimen for measuring residual stress at room temperature and another one is used for measuring residual stress after fire exposure. In order to reduce the influence of flame cutting ends on the measured results of residual stress, the columns were cutting into three segments (testing segment is the middle one) by using Wire cut Electrical Discharge Machining. The testing segment is $300 \mathrm{~mm}$ in length and the two others segments are $430 \mathrm{~mm}$ in length, which is longer than required length (1.5 2.0 times of section height). Previous experimental researches have shown that, the distance of test section from the member end must be far enough in order to reduce the influence of end, and a distance of 1.5 to 2.0 times the lateral dimensions is required [9]. The strips are about $10 \mathrm{~mm}$ in width and $300 \mathrm{~mm}$ in length, with two gauge holes at two ends, and the distance between the two gauge holes is $250 \mathrm{~mm}$. The cutting order of segments and strips dimension is shown in Figure 2.

The instruments used in the strips preparation include Wire-cut Electrical Discharge Machine, Electric Hole-drilling Machine and Hand-hold Strain Gauge. The cutting lines and centers of gauge holes are marked on the sectioning regions. Corresponding to center markers, through thickness holes are drilled by the drilling machine. In order to reduce the variation of gauge length, gauge holes are centrally located by using a punch. By using this method, strain measurements can be taken over a $250 \mathrm{~mm}$ gauge length using the hand-hold strain gauge. The minimum scale value of strain gauge is $0.001 \mathrm{~mm}$. The original gauge lengths were measured and recorded. Three sets of measurements for each gauge length were taken if measurement variation does not exceeds 0.005 $\mathrm{mm}$. Temperature changes during readings are practically eliminated by using a reference bar at the first and last of each measurement set. The sectioning segment is cut out with Wire cut Electrical Discharge Machining. Then, the sectioning proceeds are performed on a milling machine as shown in Figure 3. The influence of released heat from mechanical milling can be suppressed by supplying fluid coolant. The middle strips of specimen on flange and web are $10 \mathrm{~mm}$ and $13 \mathrm{~mm}$ in width, other strips are about 14 or $15 \mathrm{~mm}$ in width before released from specimens. Strips sectioned from the same specimen are put together in orders, as shown in Figure 4. Iron filings and grease need to be cleaned from the sectioned strips, especial around gauge holes. Three sets of gauge length are measured again following the procedure recommended in Ref. [9]. The released strains can be computed from the measured strains and temperature compensations. 

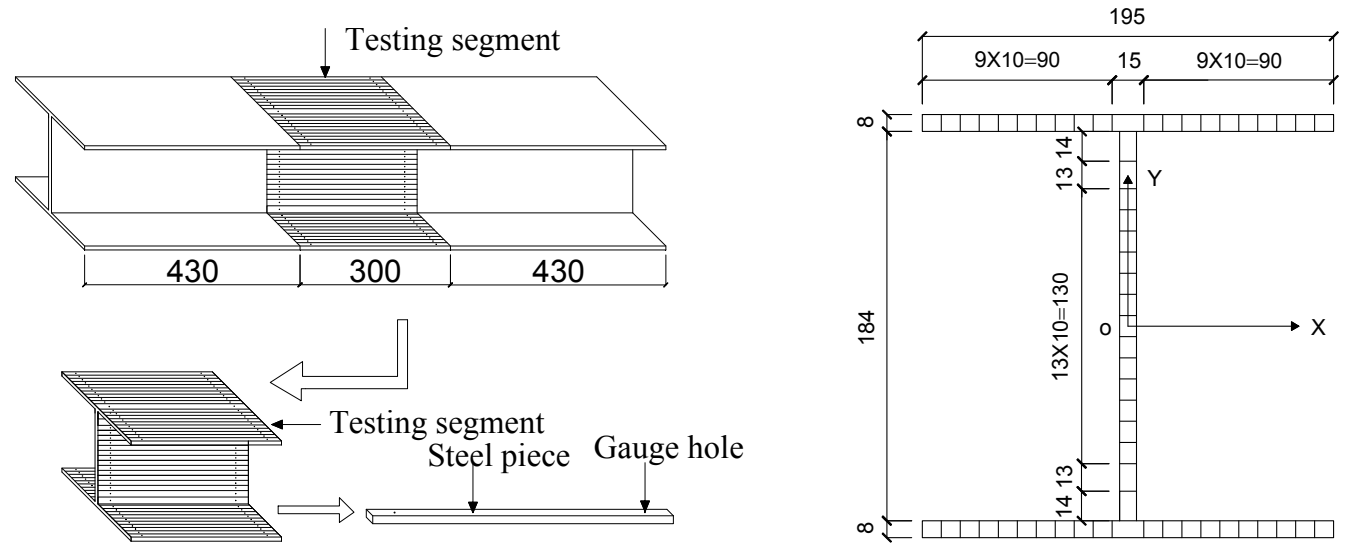

Figure 2. Cutting Order and Trip Dimensions (mm)

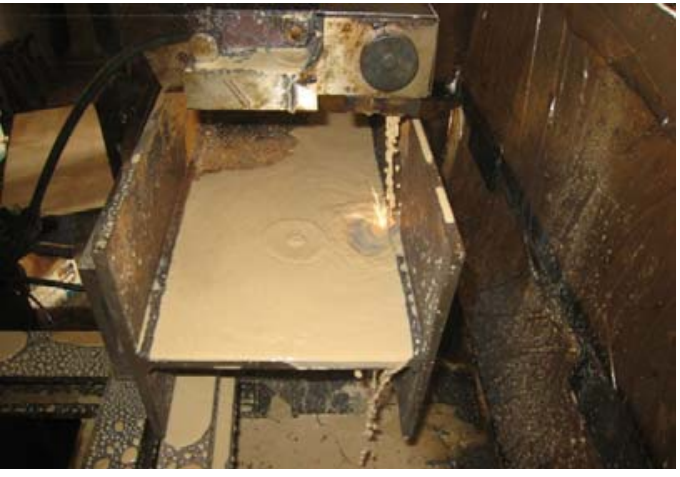

Figure 3. Sectioning Procedure of H-shaped Section

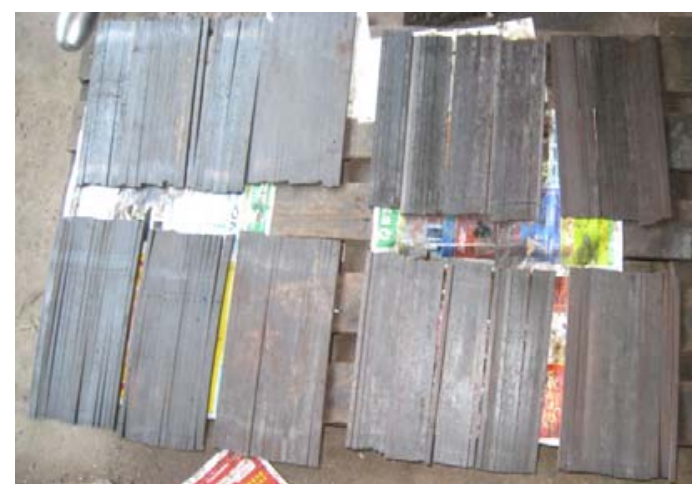

Figure 4. Sectioned Strips

In order to investigate the effect of fire exposure on the residual stress of mild steel, testing is also conducted on Q235 steel specimen. The preparation and process of Q235 steel specimen is same to the high strength Q460 steel except that the Q235 steel is hot-rolling H-shaped section and the dimension of cross section is $\mathrm{H} 194 \times 150 \times 9 \times 6$ (height $\times$ width $\times$ flange thickness $\times$ web thickness). The measured yield strength of mild Q235 steel used in the specimen is $280 \mathrm{MPa}$.

For the specimens used to measure residual stress after fire exposure, the steel columns are put into a furnace and the furnace is started to follow ISO-834 standard temperature curve for a period until the temperature of steel reaches $600{ }^{\circ} \mathrm{C}$. The cooling phase of furnace is obtained by natural cooling. After the temperature of column approaches room temperature, the trips begin to prepare and the procedures are same as those for measuring residual stress before fire exposure. The temperature of furnace and steel specimen during heating and cooling is shown in Figure 5. It can be observed that the temperature of steel columns increases slowly than the furnace even though the length of columns is only 1.16 meters in length. This is due to the temperature increase of steel member in high temperature has great relation with shape of cross section instead of length of specimen. 


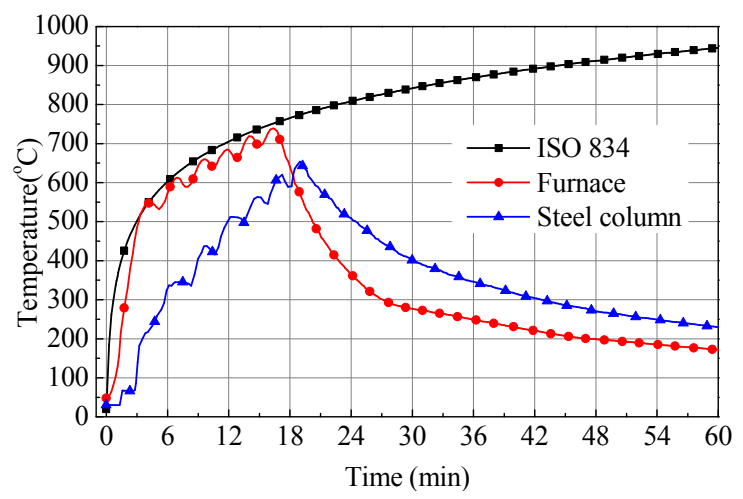

Figure 5. Temperature-time Curve for Furnace and Steel Column

\subsection{Testing Procedures}

The testing procedure comprises the following steps:

(1) Drilling holes

Before drilling gauge holes, it is necessary to clean the rust on the surface of steel by polishing. Then the cutting lines are drawn on the surface to mark the boundary of strips and then a sign is marked on each trip. In order to compensate the influence of temperature variation on the measured strain, a reference bar is fabricated to consider the temperature strain. Finally, the gauge holes are drilled on the sectioned segment with a strain gauge length of $250 \mathrm{~mm}$. The diameter of gauge hole is $0.5 \mathrm{~mm}$.

(2) Measuring gauge length

After cleaning the dust in the gauge holes, the length of standard strips, temperature compensating strips and the distance between gauge holes are measured for three times. According to the difference of standard trip and temperature compensating segment and sectioned strips, the length of temperature compensating segment and gauge holes can be calculated. If the difference of the three results exceeds $0.015 \mathrm{~mm}$, the results are abandoned and measured again. Otherwise, the average value of three results is represented as gauge length of temperature compensating segment $\left(L_{\mathrm{T} 1}\right)$ and sectioned trips $\left(L_{1}\right)$.

(3) Cutting strips

Along the lines on the surface of columns, the column is cut into three segments and then the sectioning segment is cut into many strips. Finally, the coolant on the surface and gauge holes of strips is cleaned.

(4) Measuring gauge length after sectioning

Similar to the step (2), the distance between two gauge holes on each strip and the length of temperature compensating segment are measured again to obtain the new length after the residual stress releases and the temperature changes. The average value of three results is represented as gauge length of temperature compensating segment $\left(L_{\mathrm{T} 2}\right)$ and sectioned trips $\left(L_{2}\right)$. 
(5) Computing the residual stress

Based on the measured results in step (2) and (4), the strain of temperature compensating segment can be obtained by $\varepsilon_{T}=\left(L_{T 2}-L_{T 1}\right) / L_{T 1}$; and the strain of strip can be calculated with $\varepsilon=\left(L_{2}-L_{1}\right) / L_{1}$. The bending deformation of strip needs to be modified by [9]

$\bar{\varepsilon}=\varepsilon+(f / l)^{2} /\left(6(f / l)^{4}+1\right)$

where $f$ is deflection of strips at mid-span and $l$ is the length of strip.

The strain generated by residual stress release can be obtained by subtracting temperature compensating strain from the total strain of strip, that is $\varepsilon_{r}=\varepsilon-\varepsilon_{T}$. According to Hooke's law, the residual stress on each trip can be obtained as $\sigma_{\mathrm{r}}=\mathrm{E} \varepsilon_{r}$.

\section{EXPERIMENTAL RESULTS AND DISCUSSION}

\subsection{Experimental results}

The residual stress distribution for the whole section is shown in Figure 6 and Figure 7 for high strength Q460 steel and mild Q235 steel, respectively. Using the measured residual stress before fire exposure, the equilibrium condition for the cross section is checked. Theoretically, since no external forces exist, equilibrium requires that the integration of the force over the whole section must be zero. For this particular case, a difference of $0.75 \mathrm{kN}$ and $1.8 \mathrm{kN}$ in tension is computed. This small difference may be attributed to the effect of saw cutting and accumulated experimental errors [9].

From the Figure 6, one can find that the maximum residual stress of high strength Q460 steel is about $300 \mathrm{MPa}$, which is approximate $50 \%$ of the yield strength. After fire exposure, the residual stress reduces significantly due to the reduction of yield strength and creep behavior of steel at high temperature, which results in the elastic deformation changing to plastic deformation. The maximum value of residual stress after fire exposure is about $70 \mathrm{MPa}$, which is only $12 \%$ of yield strength. For mild Q235 steel (as shown in Figure 7), similar trend can be observed and maximum residual stress before and after fire exposure are $180 \mathrm{MPa}$ and $85 \mathrm{MPa}$, which are $65 \%$ and $30 \%$ of yield strength, respectively.

\subsection{Discussion}

The comparison of residual stress distribution before and after fire exposure for high strength Q460 steel is shown in Figure 8. As can be seen from the figure, the residual stress distribution mode both on flange and web before fire exposure is similar to that after fire exposure. The distribution mode looks like a "W" on the flange and " $U$ " on the web. However, the maximum value after fire exposure decreases obviously. For the residual stress at the middle of flange, the reduction factor after fire exposure is 0.23 . For the residual stress at middle of web, the residual stress almost disappears after fire exposure. 


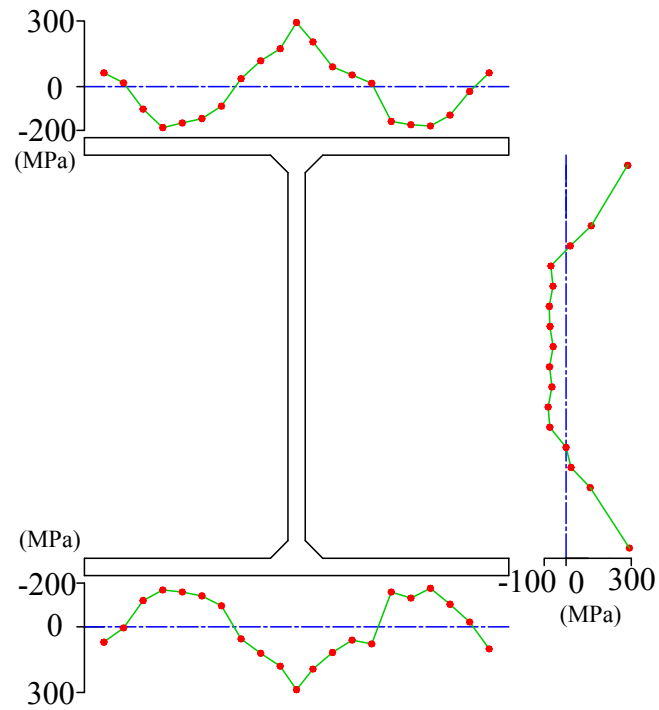

(a) Before fire exposure

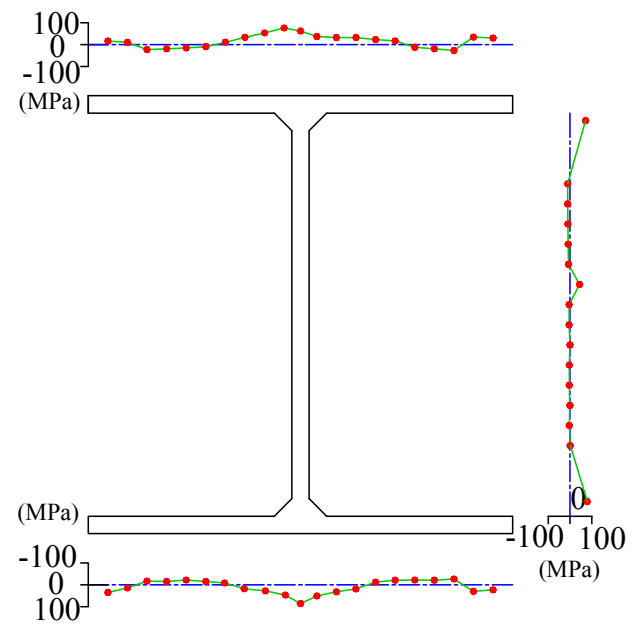

(b) After fire exposure

Figure 6. Residual Stress Distribution in High Strength Q460 Steel Section

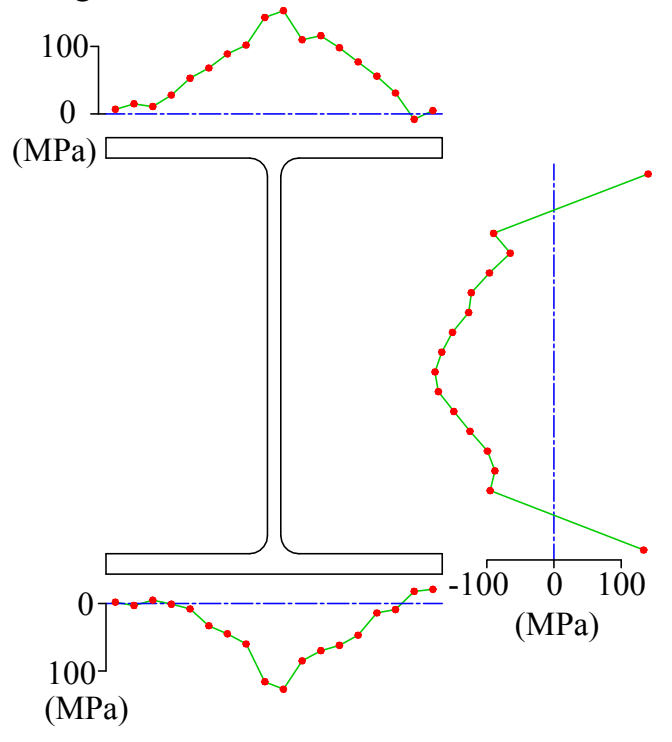

(a) Before fire exposure

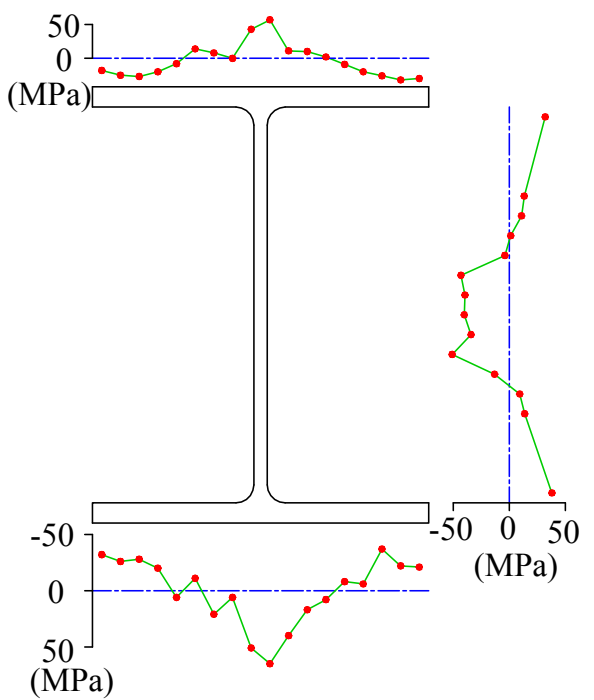

(b) After fire exposure

Figure 7. Residual Stress Distribution in Mild Q235 Steel Section

The comparison of residual stress distribution before and after fire exposure for mild Q235 steel is shown in Figure 9. It can be seen that on the flange, the distribution mode looks like an inverse "V". The distribution mode on the web is similar to that for high strength Q460 steel. After fire exposure, the maximum value of residual stress on the flange reduces significantly but not as much as that of high strength Q460 steel and there is still 40\% residual stress left compared to that before fire exposure. For the web, the reduction is obvious and $25 \%$ left, which is almost same as that of high strength Q460 steel. 


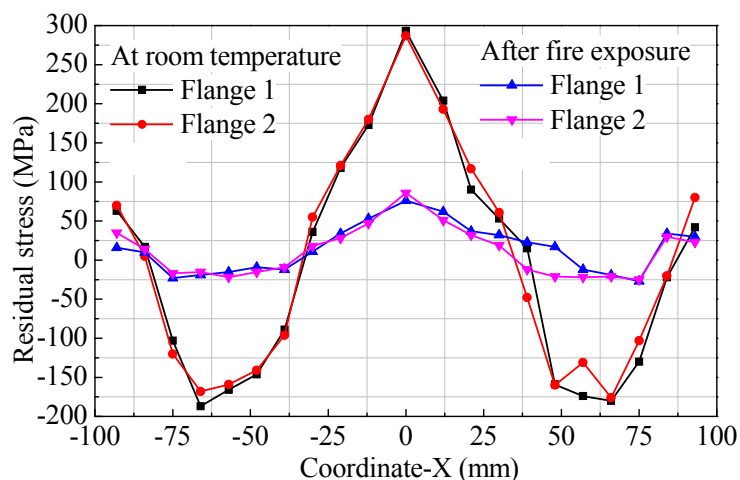

(a) Flange

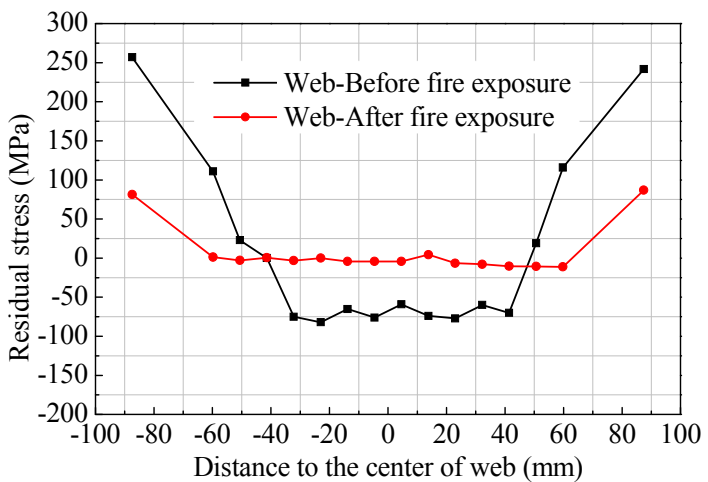

(b) Web

Figure 8. Comparison of Residual Stress of High Strength Q460 Steel before and after Fire Exposure

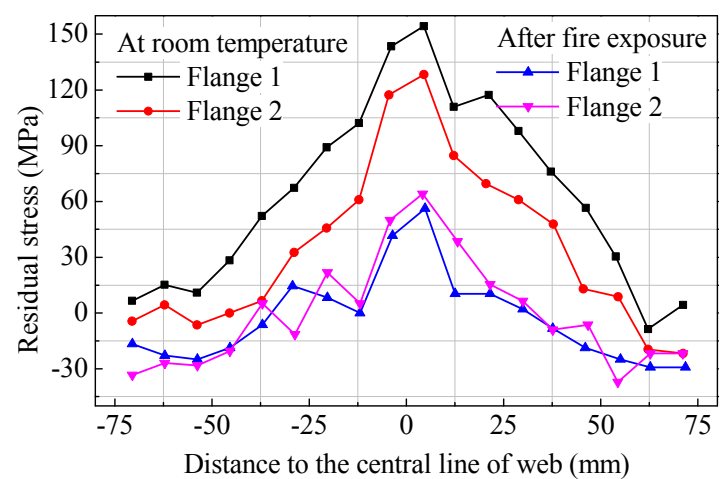

(a) Flange

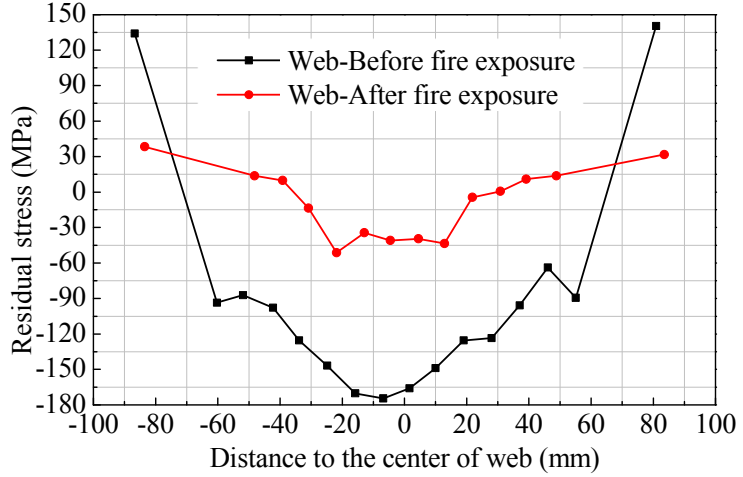

(b) Web

Figure 9. Comparison of Residual Stress of Mild Q235 Steel before and after Fire Exposure

The distribution mode between high strength Q460 steel and mild steel are different due to the difference of fabrication method. For the high strength Q460 steel, the plate is obtained by flame cutting and the section is compositing by welding; and for the mild Q235 steel, the plate and section is hot rolled. From the testing results of residual stress after fire exposure, it can be found that, the residual stress generated by welding is relative easy to reduce by tempering.

\section{FINITE ELEMENT ANALYSIS}

As to now, there is no proper method to measure the residual stress distribution at high temperature and the residual stress must be reducing at high temperature based on the intuitive judgment. Finite element method is very powerful and proved to be capable to analysis welding residual stress. In order to quantity the residual stress of high strength Q460 steel welded H-shaped section at high temperature, finite element analysis was performed by employing ANSYS soft package.

\section{1 $\quad$ Finite element model}

Two models are established to obtain the residual stress generated by flame cutting and welding, namely thermal model and structural model. 


\subsubsection{Thermal model}

The thermal model in ANSYS is created using two types of elements, namely SOLID70 and SOLID90. SOLID90 is a higher order version of the element SOLID70. Only at the transition zone, SOLID90 is used and at the other zone, SOLID70 is used. SOLID70 element has eight nodes with a single degree of freedom, temperature, at each node. The element is applicable to a three-dimensional, steady-state or transient thermal analysis.

For the flame cutting simulation, a defined high temperature is applied on the edge of flange (4 mm width form the boundary of flange) and the temperature for all the other area keeps ambient. Then transient thermal analysis is performed until the temperature reduces to room temperature. Based on the literatures [11] and [12], $600^{\circ} \mathrm{C}$ is adopted to apply thermal boundary on the $4 \mathrm{~mm}$ width of the two edges of flange. For simulation of welding, a mobile heat source generated internally is adopted to simulate the heat input during welding on the element of weld [13], and the temperature for all the other elements keeps ambient. The heat generation per time unit can be obtained by

$Q=\eta U I$

where $Q$ is heat generation in per time unit; $\eta$ is heat efficiency of welding, can be adopted as $0.65 \sim 0.9$ [14], in this paper $\eta=0.85$; $\mathrm{U}$ is voltage of welding and it is $24 \mathrm{~V}$; I is electric current of welding and it is $180 \mathrm{~A}$.

The heat generation rate can be obtained by

$q=Q / V$

where $V$ is welding volume per time unit, can be computed with welding speed $(6 \mathrm{~mm} / \mathrm{s})$ and thickness of weld leg $(8 \mathrm{~mm})$.

When applying heat generation rate of weld mobile heat source on element, "birth and death" function of element is used. Before welding simulation starts, all welding elements are killed (death). When applying hear generation rate on a welding element, this element is activated (birth). After the heat source moves away, the activated elements are killed again. In this way, the temperature distribution during welding can be simulated.

\subsubsection{Structural model}

In the structural analysis, SOLID185 and SOLID186 are used. Corresponding to thermal model, SOLID186 only is used for transition zone. SOLID185 element is defined by eight nodes having three degrees of freedom at each node. The element has plasticity, hyperelasticity, stress stiffening, creep, large deflection, and large strain capabilities. In order to improve analysis efficiency, only half of column $(600 \mathrm{~mm})$ is established. Figure 10 shows the dimension and discertized of H-shaped welded column. At the flame cutting zone and welding part, the temperature varies rapidly and the mesh is discertized densely. 
After performing thermal analysis, the temperature distribution is saved and read into structural analysis to obtain the residual stress distribution. In the structural analysis, the boundary condition of the column is set up according to the realistic condition during welding. All the nodes on one end of column are restrained in three directions and for the nodes on another end are restrained in two directions except the axial direction. Therefore, the columns can expand freely along the axial direction.
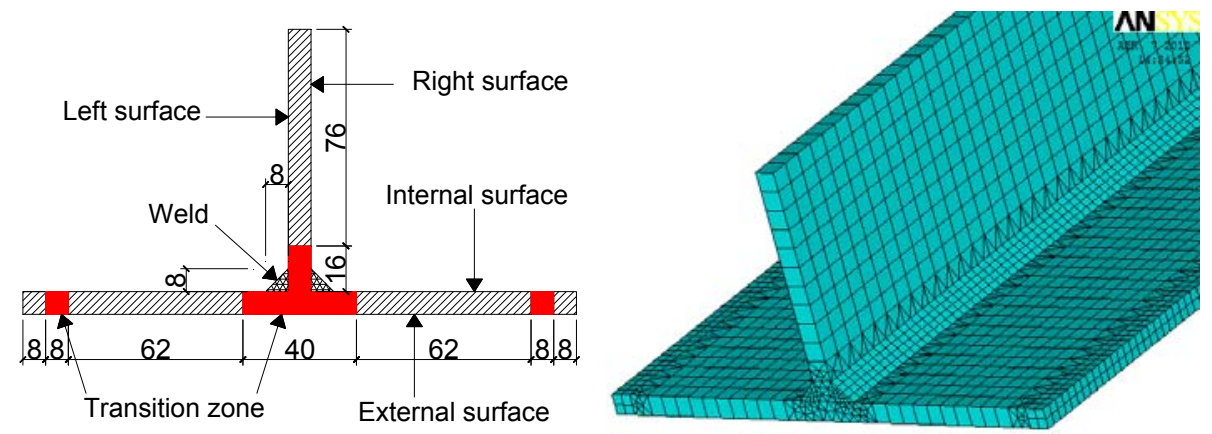

Figure 10. Finite Element Model

\section{$5.2 \quad$ Temperature Distribution}

The temperature distribution after cutting on flange is shown in Figure 11. Due to high thermal conductivity of steel, the heat on the edge is transferred quickly to the middle of plate and to the atmosphere. As can be seen from Figure 11, One minute and forty seconds later, the maximum temperature is about $80{ }^{\circ} \mathrm{C}$ and ten thousand seconds (approximate 2.8 hours) later, the temperature is close to room temperature $\left(27{ }^{\circ} \mathrm{C}\right)$.

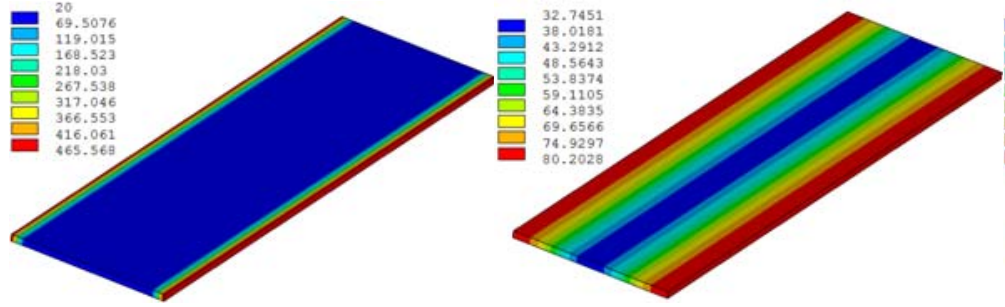

(a) $\mathrm{t}=2 \mathrm{~s}$ (b) $\mathrm{t}=100 \mathrm{~s}$

Figure 11. Temperature Distribution of Flame Cutting

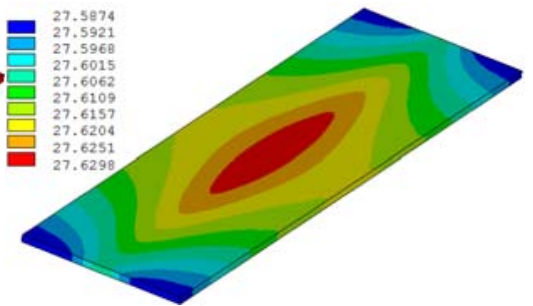

(c) $\mathrm{t}=10000 \mathrm{~s}$

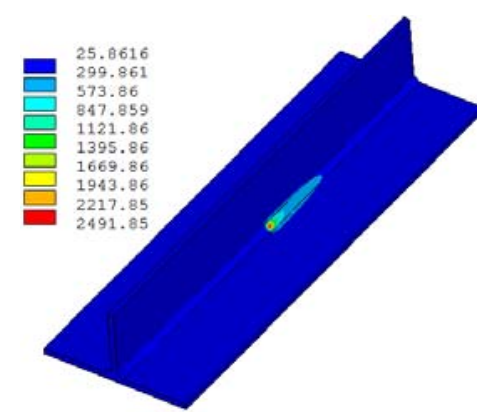

(a) $\mathrm{t}=150 \mathrm{~s}$

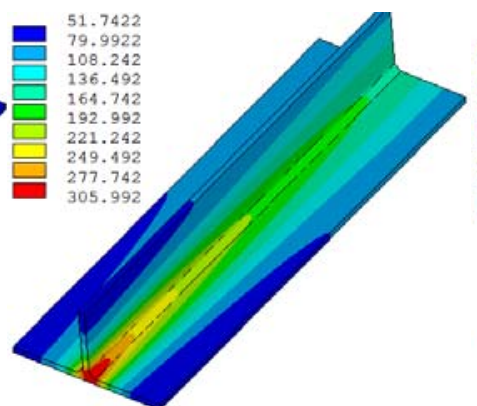

(b) $\mathrm{t}=220 \mathrm{~s}$

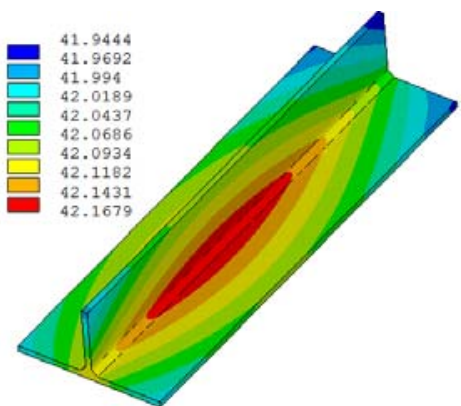

(c) $\mathrm{t}=12200 \mathrm{~s}$

Figure 12. Temperature Distribution of Steel Column during Welding 
The temperature distribution of welding simulation is shown in Figure 12. The column is $600 \mathrm{~mm}$ in length and the welding speed is $6 \mathrm{~mm}$ per second. Therefore the welding time for the two filled weld may last for 200 seconds. As is shown in Figure 12, during the welding, the temperature is very high at the welding location and the maximum temperature reaches to $2500{ }^{\circ} \mathrm{C}$. Twenty seconds later after finishing welding, the maximum temperature reduces to about $306 \square$ and 12000 seconds ( 3 hours and twenty minutes) later; the temperature reduces to room temperature. The temperature-time curves for two welding element at middle and quarter span are shown in Figure 13. It is shown that when welding the rear welding element, the temperature of the welding element increases and reaches about $250 \square$; and when the welding reaches the welding element, the temperature increases sharply and reaches $2500 \square$ in few seconds.

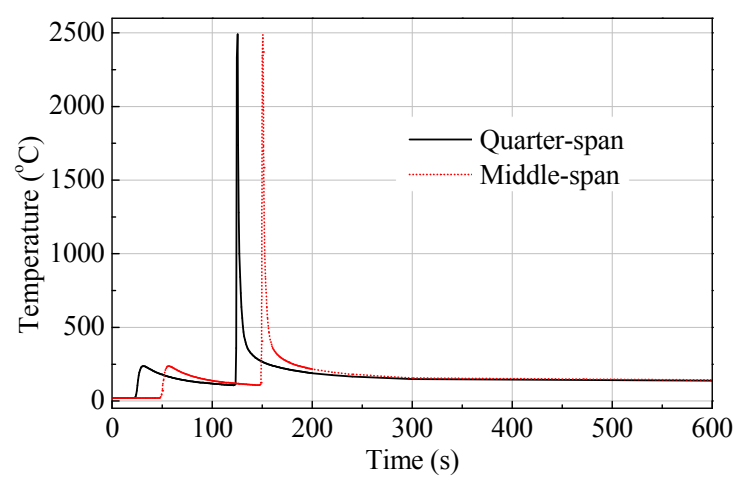

Figure 13. Temperature-time Curves for Two Welding Elements during Welding

\subsection{Stress Distribution before Fire Exposure}

The residual stress distribution on the whole section after flame cutting and welding are shown in Figure 14. For the right surface of web, the values of residual stress at the ends of web are irregular and omitted. From the Figure 14, it can be seen that at the area of flame cutting welding, the residual stress is very significant tension stress and reaches to $60 \%$ of yield strength. The residual stress in these two areas mainly generated due to non-uniform cooling of cutting and welding. At the other portion of section, the compressive residual stresses in flange or web are much lower compared to tension stress. This is caused by the greater tensile residual stresses in the same section, which are balanced by compressive stresses to maintain internal equilibrium.

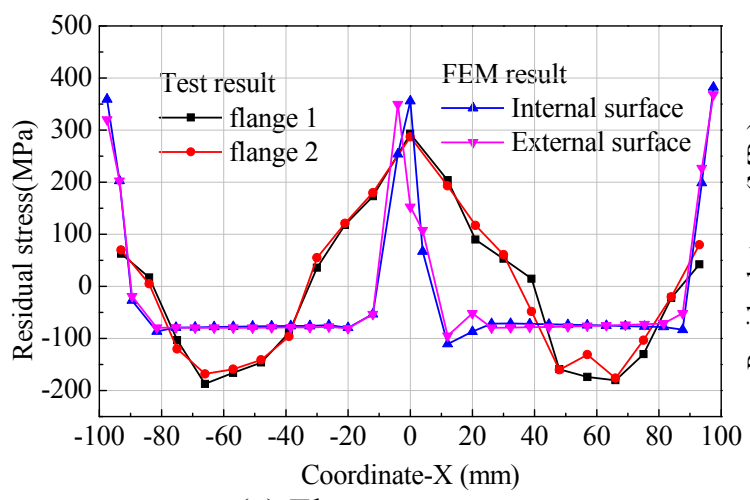

(a) Flange

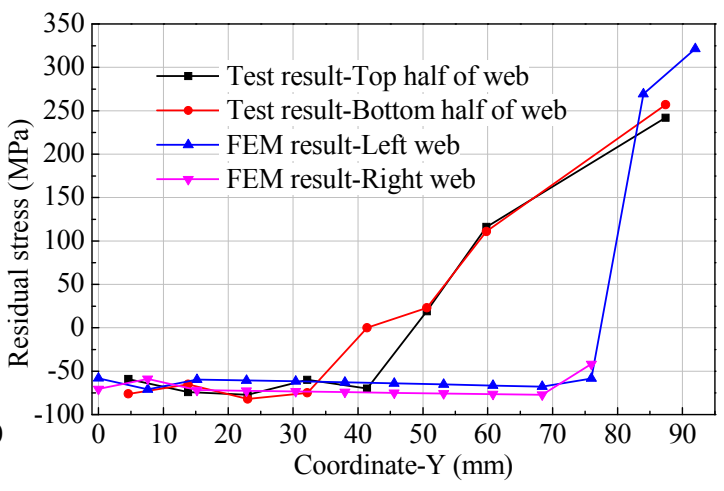

(b) Web

Figure 14. Comparison of Residual Stress between Test and FEM before Fire Exposure 


\subsection{Comparison and Discussion}

The comparison between experimental and analyzed results is also shown in Figure 14. As can been seen from the figure, the maximum values of residual stress at the middle of flange, half and ends of web are agreeable. At the middle of flange, the difference between them is $63 \mathrm{MPa}$ (account for $20 \%$ of experimental result). At the end of web, the difference between them is $64 \mathrm{MPa}$ (account for $20 \%$ of experimental result). However, at the flange cutting area, the difference is significant. It may be attributed to two reasons. One is that the simplified approach was used to simulate the temperature distribution at this portion and the temperature decrease too quickly, which results in the results of FEM is higher than test. Another reason is that the experimental results in one segment is average value of the whole width of segment and it is much lower that the real maximum value. In addition, the residual stress curves obtained by experiment are smoother than that of analyzed results. This may be attributed to that in the finite element model, only residual stress produced by welding and flange cutting is considered and the residual stress generated by rolling is neglect. In the experiment, the section is welded by three steel plates, which have residual stress when hot-rolling before welding. In general, the analyzed results agree with experimental data with an acceptable range.

\subsection{Post-fire Residual Stress Distribution}

After obtaining the residual stress distribution by simulating the flame cutting and welding, post-fire residual stress distribution is simulated by thermal analysis and structural analysis. The fire scenario is ISO-834 standard fire. The comparison of temperature-time curve for the columns obtained by finite element analysis and experiment is shown in Figure 15. It can be seen that the analyzed temperature during heating and cooling agree well with test data.

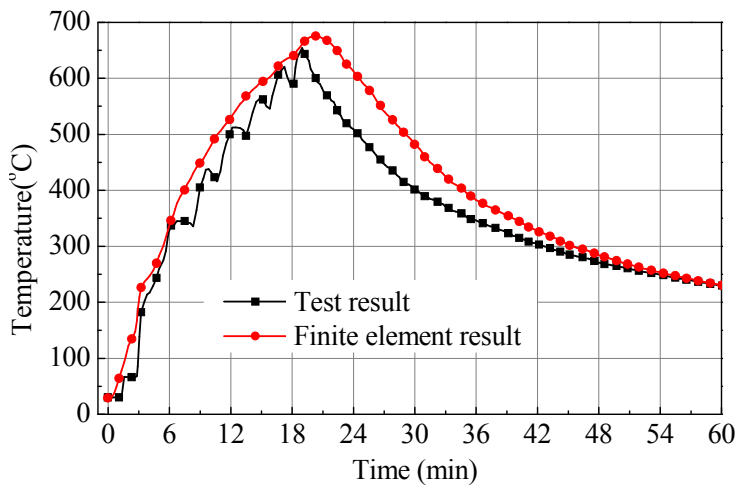

Figure 15. Comparison of Temperature between Finite Element Analysis Results and Test Results

The residual stress generated by flame cutting and welding is imported to the structural model as well as the temperature distribution during heating and cooling, the post-fire residual stress can be obtained. The analyzed results of post-fire residual stress and the comparison of the results with test data are shown in Figure 16. Generally, the residual stress reduces significantly after fire exposure. At the two ends and middle of flange, there is a big difference between analyzed results and test data due to the following possible reasons. Firstly, in the finite element model, the residual stress produced by hot-rolling is not considered to simplify the analysis procedure. Secondly, the element dimension is not small enough in order to improve the computing efficiency. Even though, the trend of residual stress variation is agreeable and the method and model can be employed to analysis the residual stress distribution at high temperatures. 


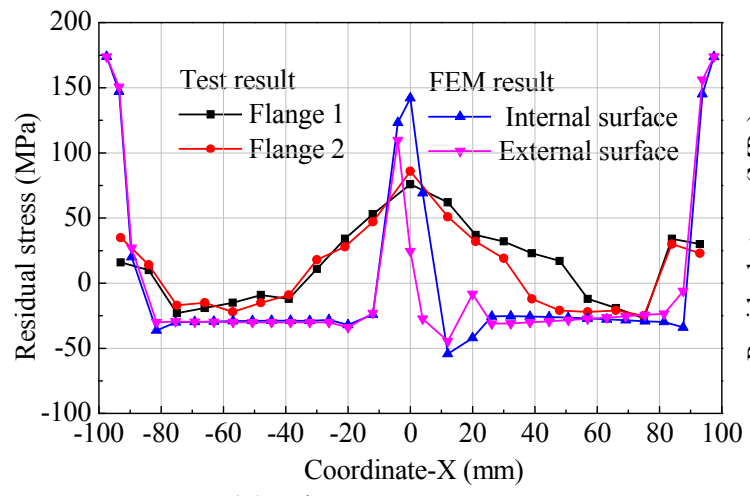

(a) Flange

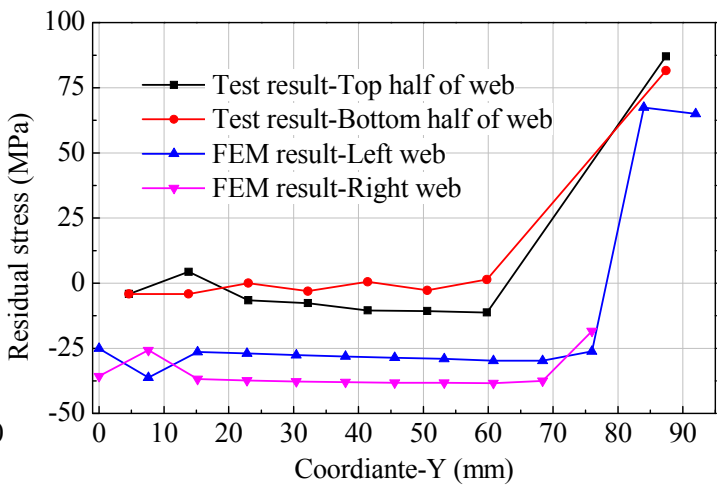

(b) Web

Figure 16. Comparison of Residual Stress between Test and FEM after Fire Exposure

\subsection{Residual Stress Distribution at High Temperatures}

The residual stress distribution at temperatures $100 \square \sim 800 \square$ was analyzed and the reduction factor of maximum values at end of the flange, one fourth width of the flange, half width of the flange, end of the web and half of the web with the elevation of temperature are shown in Figure 17. As can be seen from Figure 17, the maximum values of residual stress decrease with the increase of temperature except at the position of middle of web. When the temperature is lower than $400{ }^{\circ} \mathrm{C}$, the maximum values of residual stress at edge of the flange, half width of the flange and end of the web almost keep constant and then decrease sharply with the elevation of temperature. This can be attributed to that when the temperature exceeds $400{ }^{\circ} \mathrm{C}$, the thermoplastic deformation will arise and the deformation will results in the redistribution of residual stress. For the position of middle of web, the residual stress increase within the temperature of $600{ }^{\circ} \mathrm{C}$ may be attributed to the complex redistribution of residual stress, including the variation of width of tension or compression areas. The further study will be investigated in the following research.

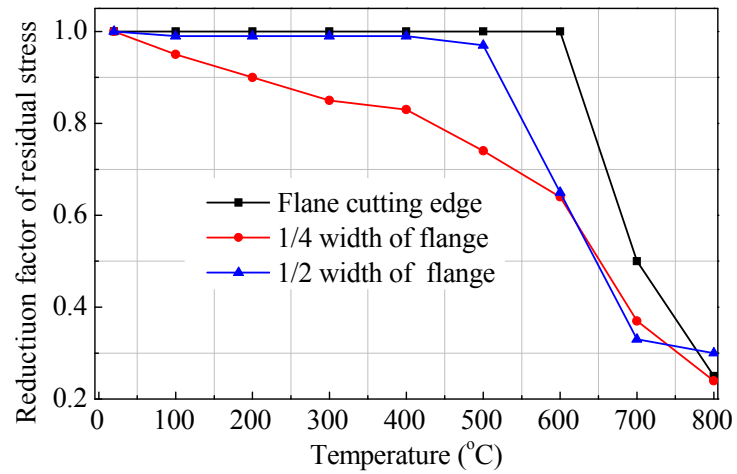

(a) Flange

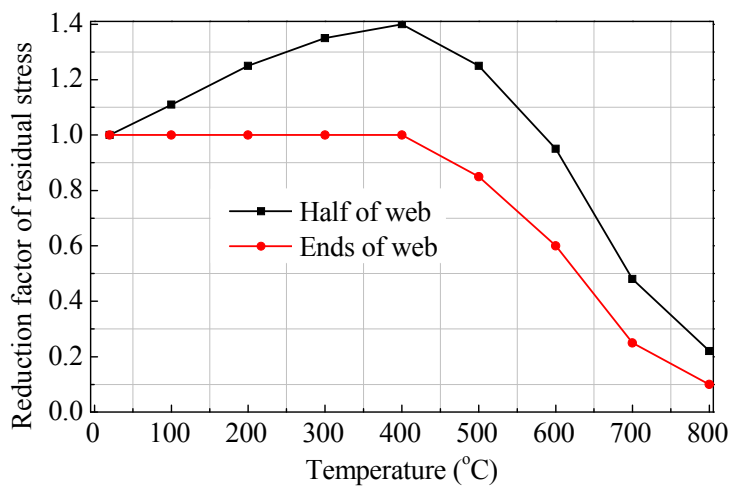

(b) Web

Figure 17. Reduction Factor of Residual Stress of High Strength Q460 Steel at High Temperatures 


\section{CONCLUSIONS}

Based on the results presented in this paper, the following conclusions can be drawn:

(1) After fire exposure, the residual stress reduces significantly for welded H-shaped section fabricated with high strength Q460 steel.

(2) At high temperature, the maximum value of residual stress varied and should be put into consideration in fire resistance design of high strength steel structures.

(3) The finite element can be used to simulate the residual stress distribution at high temperature and after fire exposure with an acceptable accuracy.

In addition, the test data presented in this paper can be used to provide validation to other researchers as well as provide a reference for fire resistance design of high strength Q460 steel.

\section{NOTATIONS}

The following symbols are used in this paper:

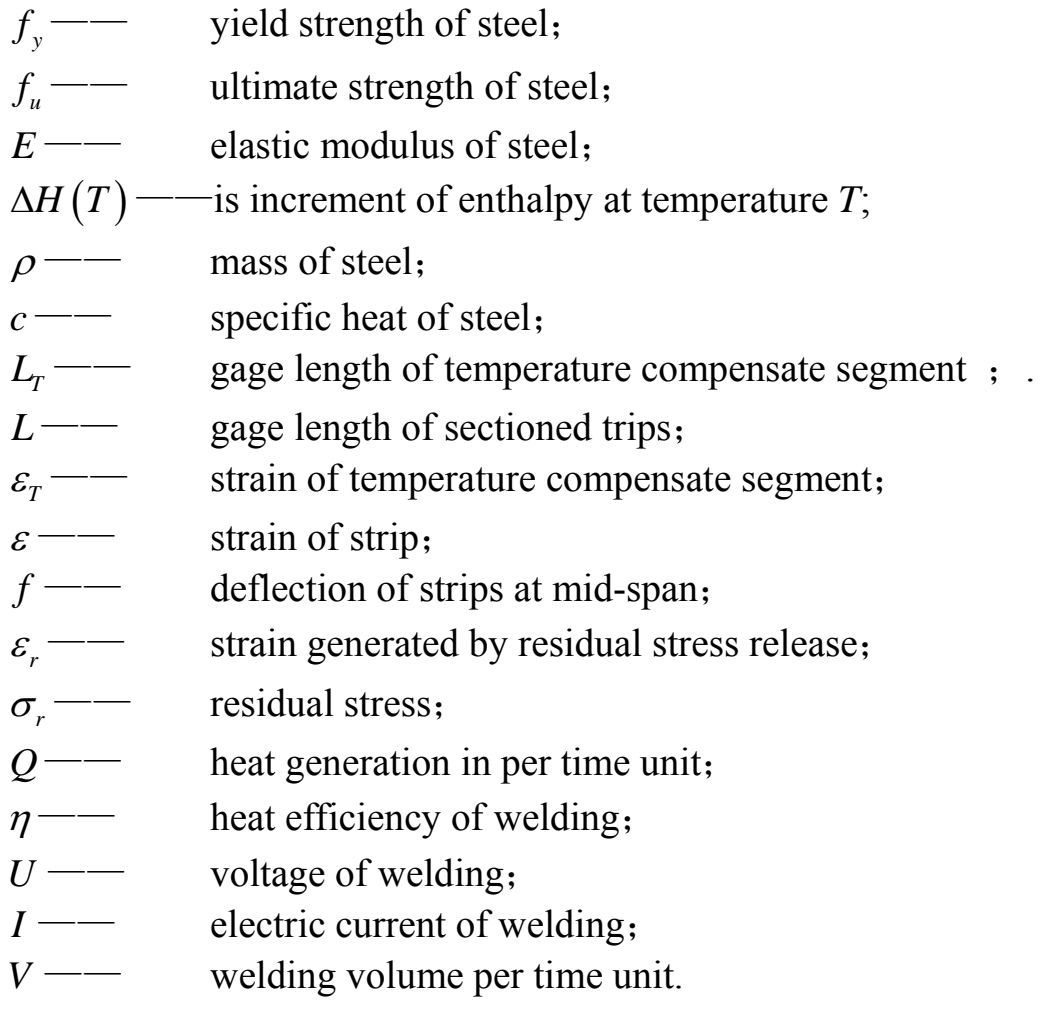

\section{ACKNOWLEDGMENT}

The authors wish to acknowledge the support from the Fundamental Research Funds for the Central Universities (Grant No.: CDJZR12200004 and 106112013CDJZR200006), China Postdoctoral Science Foundation (Grant No.:20110490811 and 2012T50765) and Funding Plan or Young Teachers in Universities of Chongqing. The support from State Key Lab for Disaster Reduction in Civil Engineering of Tongji University in China is also greatly appreciated. Any opinions, findings, and conclusions or recommendations expressed in this paper are those of the authors and do not necessarily reflect the views of the sponsors. 


\section{REFERENCE}

[1]. Shi, G, Shi, Y.J. and Wang, Y.Q., "Engineering Application of Ultra-High Strength Steel Structures”, Progress in Steel Building Structures, 2008, Vol. 10, No. 4, pp. 32-38. (In Chinese )

[2]. Beedle, L.S., "Stability of Metal Structures- A World View”, 2nd Ed. Structural Stability Research Council, 1991.

[3]. Tebedge, N. and Tall, L., "Residual Stress in Structural Steel Shapes - A Summary of Measured Values”, Fritz Laboratory Report; February 1973.

[4]. Cruise, R.B. and Gardner, L., "Residual Stress Analysis of Structural Stainless Steel Sections", Journal of Constructional Steel Research, 2008, Vol. 64, pp. 352-66.

[5]. Wang, Y.B., Li, G.Q. and Chen, S.W., "The Assessment of Residual Stress in Welded High Strength Steel Box Sections", Journal of Constructional Steel Research, 2012, Vol. 76, pp.93-99.

[6]. Wang, W.Y., Liu, B. and Kodur, V.K.R., "Effect of Temperature on Strength and Elastic Modulus of High Strength Steel”, Journal of Materials in Civil Engineering-ASCE, 2013, Vol. 25, No. 2, pp. 174-182.

[7]. Qiang, X., Bijlaard, F.S.K. and Kolstein, H., "Deterioration of Mechanical Properties of High Strength Structural Steel S460N under Steady State Fire Condition”, Materials and Design, 2012, Vol. 36, No. 1, pp. 438-442.

[8]. European Committee for Standardization, ENV 1993-1-2, "Eurocode 3, Design of Steel Structures, Part 1.2: General Rules-Structural Fire Design”, 2001.

[9]. Tebedge, N., Alpsten, G. and Tall, L., "Residual-stress Measurement by the Sectioning Method", Experimental Mechanics, 1973, Vol. 13, pp. 88-96.

[10]. Withers, P.J. and Bhadeshia, H.K.D.H., "Residual Stress: Part 1 - Measurement Techniques", Materials Science and Technology, 2001, Vol. 17, No. 4, pp. 355-65.

[11]. Chen, J., "GJ Measurement and Analysis on Residual Stress in Welded I-shaped Cross-sectional Member", Master's degree thesis, Chongqing University, Chongqing, 2010.

[12]. Huang, H., "Research on Residual Stress of Plate Oxygen Cutting based on Numerical Simulation and Experiment", Master's degree thesis, Dalian University of Technology, Dalian, 2010.

[13]. Wang, J.F., "Heat Source Model Study on Weld Temperature Filed and Stress Field", Master's Degree Thesis, Yanshan University, Qinghuadao, 2006.

[14]. Cheng, S.L., "Numerical Analysis on Weld Residual Stress based on Temperature and Stress Field”, Master's Degree Thesis, Nanchang University, Nanchang, 2007. 